\title{
Meningococcal serogroups A, C,W-I35, and $Y$ tetanus toxoid conjugate vaccine: a new conjugate vaccine against invasive meningococcal disease
}

This article was published in the following Dove Press journal:

Infection and Drug Resistance

3 April 2014

Number of times this article has been viewed

\section{Carine P Hedari* \\ Rima W Khinkarly* \\ Ghassan S Dbaibo}

Center for Infectious Diseases Research, Division of Pediatric Infectious Diseases, Department of Pediatrics and Adolescent Medicine, American University of Beirut Medical Center, Beirut, Lebanon

*These authors contributed equally to this work
Correspondence: Ghassan S Dbaibo Department of Pediatrics and Adolescent Medicine, Director, Center for Infectious Diseases Research, American University of Beirut Medical Center, PO Box I I-0236, Riad El-Solh, Beirut, Lebanon Tel +96| I 374444 ext 5752

Fax +96 | 137078 |

Email gdbaibo@aub.edu.lb
Abstract: Invasive meningococcal disease is a serious infection that occurs worldwide. It is caused by Neisseria meningitidis, of which six serogroups (A, B, C, W-135, X, and Y) are responsible for most infections. The case fatality rate of meningococcal disease remains high and can lead to significant sequelae. Vaccination remains the best strategy to prevent meningococcal disease. Polysaccharide vaccines were initially introduced in the late 1960s but their limitations (poor immunogenicity in infants and toddlers and hyporesponsiveness after repeated doses) have led to the development and use of meningococcal conjugate vaccines, which overcome these limitations. Two quadrivalent conjugated meningococcal vaccines - MenACWY-DT (Menactra $\left.{ }^{\circledR}\right)$ and MenACWY-CRM ${ }_{197}\left(\right.$ Menveo $\left.^{\circledR}\right)$ - using diphtheria toxoid or a mutant protein, respectively, as carrier proteins have already been licensed in the US. Recently, a quadrivalent meningococcal vaccine conjugated to tetanus toxoid (MenACWY-TT; Nimenrix ${ }^{\circledR}$ ) was approved for use in Europe in 2012. The immunogenicity of MenACWY-TT, its reactogenicity and safety profile, as well as its coadministration with other vaccines are discussed in this review. Clinical trials showed that MenACWY-TT was immunogenic in children above the age of 12 months, adolescents, and adults, and has an acceptable reactogenicity and safety profile. Its coadministration with several other vaccines that are commonly used in children, adolescents, and adults did not affect the immunogenicity of MenACWY-TT or the coadministered vaccine, nor did it affect its reactogenicity and safety. Other studies are now ongoing in order to determine the immunogenicity, reactogenicity, and safety of MenACWY-TT in infants from the age of 6 weeks.

Keywords: coadministration, immunogenicity, meningococcal conjugate vaccine, reactogenicity and safety

\section{Introduction}

Neisseria meningitidis is the leading cause of bacterial meningitis in infants, children, and young adults in countries where conjugate vaccines against Streptococcus pneumoniae and Haemophilus influenzae type b (Hib), the other two major causes of bacterial meningitis, have been added to the national immunization schedules. ${ }^{1,2}$

An estimated 500,000 cases of invasive meningococcal disease (IMD) occur annually worldwide and are a cause of significant mortality and morbidity. ${ }^{3}$ Most of them occur during respiratory viral illnesses season. ${ }^{4}$ These IMD cases represent a spectrum of diseases that includes bacteremia, meningitis, and, less commonly, pneumonia, myocarditis, pericarditis, or other diseases. They are caused by N. meningitidis, an aerobic gram-negative bacterium. This organism has a polysaccharide capsule that represents one of the bacterial virulence factors. Nonencapsulated mutants of $N$. meningitidis are serum sensitive (ie, killed by complement) and nonvirulent, and hence illustrate the importance of the capsule as a main virulence factor. ${ }^{5-7}$ 
Based on the chemical and antigenic properties of the capsule, there are at least 13 serogroups that are classified. Six of these (A, B, C, W-135, X, Y) are responsible for most of IMD cases. ${ }^{2,8,9}$

In this review, we discuss IMD and its prevention by vaccination with focus on the recently licensed quadrivalent meningococcal serogroups A, C, W-135, and Y tetanus toxoid conjugate vaccine (MenACWY-TT).

\section{Pathogenesis of invasive meningococcal disease}

$N$. meningitidis is a commensal organism of the nasopharynx. It is asymptomatically carried in most subjects but can occasionally cross into the bloodstream and cause invasive disease depending on host, environment, and organism related factors. ${ }^{10,11}$ Host risk factors include age, race, functional or anatomical asplenia, HIV infection, or complement deficiencies. ${ }^{5,12-14}$ Environmental factors also include overcrowding, prolonged exposure to an index case, and travel to endemic or hyperendemic areas. ${ }^{5}$

The duration of meningococcal carriage ranges between 5 and 9 months; however, the highest risk of disease manifestation is in the first 15 days after acquisition of the pathogen in the nasopharynx..$^{9,15,16}$

Carriage induces an immune response against the bacterium, causing the production of serum bactericidal antibodies within 2 weeks after colonization. Host defense against IMD is therefore achieved through activation of the complement cascade and binding of complement to the surface of the bacterium. ${ }^{10}$ The polysaccharide capsule helps the bacterium evade opsonization and phagocytosis.

Humoral immunity has been proven to be of utmost importance in clearing the organism. In 1969, Goldschneider et al demonstrated that susceptibility to IMD was directly related to lack of protective antibodies against pathogenic virulent strains of meningococcus, as seen with young infants who lack previous exposure and immunity. ${ }^{17}$

Meningitis is the most common presentation of IMD, ${ }^{9}$ representing around $50 \%$ of all IMD cases, followed by bacteremia, which represents around $40 \%$. Fulminant meningococcemia occurs in $10 \%-20 \%$ of these cases leading to organ failure and disseminated intravascular coagulation including Waterhouse-Friderichsen syndrome, with high mortality rates reaching $50 \%{ }^{19}$

The case fatality rate of IMD can reach up to $10 \%{ }^{9}$ Permanent sequelae occur in up to $20 \%$ of survivors in the form of neurodevelopmental disabilities, psychological disturbances, hearing and visual impairment, skin scarring, and amputation. ${ }^{20-22}$
Transmission of the disease from person to person occurs through respiratory aerosol droplets or contact with oral secretions (through kissing, sharing eating utensils, etc). ${ }^{23,24}$

\section{Serogroup distribution}

Disease patterns vary widely among regions, age groups, serogroups, and geographical location. The peak incidence of meningococcal disease occurs among children less than 2 years of age and late adolescents (16-21 years); one-third to one-half of cases are seen in adults older than 65 years ${ }^{5}$ (CDC, unpublished data, 2002-2011). Epidemics are usually characterized by the predominance of a single meningococcal genotype, higher incidence rates, and a shift toward older age groups. ${ }^{26}$

The majority of meningococcal disease occurs in developing countries. In the developed world, the incidence of meningococcal disease has decreased to less than one to three cases per 100,000 population per year; cases occur sporadically and most IMD is caused by serogroups B and C, with serogroup $C$ being associated with more fatalities than serogroup B (Figure 1). ${ }^{27}$

Serogroup A meningococcus (MenA) has been historically known as the causative agent of most meningococcal disease in the first part of the $20^{\text {th }}$ century. ${ }^{28}$ Its incidence has declined, although, until recently, it continues to be responsible for recurring huge cyclic epidemics in developing countries, particularly in the meningitis belt in sub-Saharan Africa and in southeastern Asia (including India, Mongolia, the People's Republic of China, and the Philippines). ${ }^{9}$ In these regions, case fatality rates reach up to $75 \%$ in children and adolescents. The meningitis belt refers to 22 countries in sub-Saharan Africa and extends from Ethiopia in the east to Senegal in the west. ${ }^{29}$

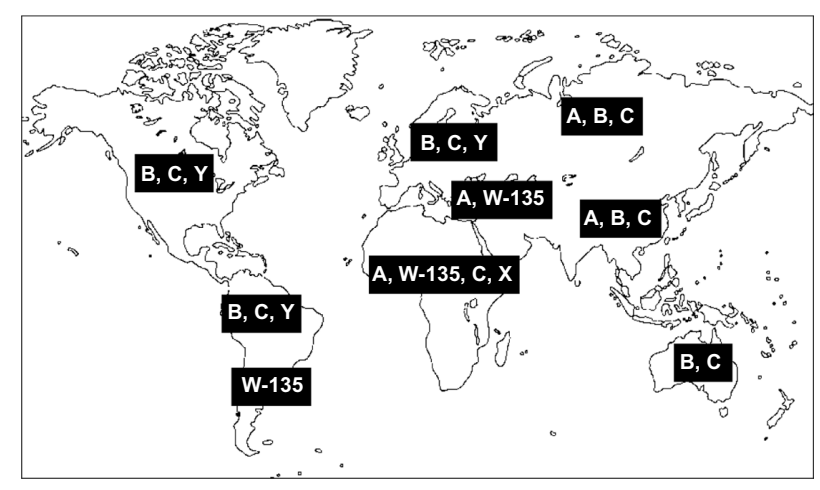

Figure I Global serogroup distribution of invasive meningococcal disease. Notes: A, serogroup A meningococcus; B, serogroup B meningococcus; C, serogroup $C$ meningococcus; $W$-135, serogroup $W$-135 meningococcus; $Y$, serogroup $Y$ meningococcus; $X$, serogroup $X$ meningococcus. 
Global incidence of serogroup B meningococcus (MenB) infection is high and is estimated to be between 20,000 and 80,000 cases per year. MenB causes endemic disease in much of the developed world ( $30 \%-40 \%$ of disease in the US and Canada and $80 \%$ in the European countries). Cases of MenB were also observed in New Zealand, Taiwan, and Thailand over the past decade. ${ }^{54}$

Serogroup C meningococcus (MenC) is also common in the developed world, has variable rates of endemic disease (currently around 30\%), and causes outbreaks. Fortunately, a lower incidence of MenC disease is currently detected in countries where MenC monovalent conjugate vaccine was introduced. ${ }^{5}$

Serogroup Y meningococcus is becoming an important cause of meningococcal disease in the USA and Canada and has been seen increasingly in the UK over the past decade. ${ }^{4,5,30}$ It usually affects older age groups and causes meningococcal pneumonia together with serogroup W-135. The latter gained particular prominence in Saudi Arabia during the Hajj pilgrimage. Before 2002, Hajj pilgrims were vaccinated against serogroups $A$ and $C$, enabling serogroup $\mathrm{W}-135$ to emerge in outbreaks during 2000-2001. ${ }^{30-32}$ Serogroup W-135 is also common in Turkey, South Africa (with an outbreak from 2003-2007), Nigeria, Argentina, and, more recently, in Chile and Brazil. ${ }^{32-34}$ By 2011, the prevalence of serogroup $\mathrm{W}-135$ had reached $31 \%$ of all IMD cases in Chile. ${ }^{35}$

Serogroup $\mathrm{X}$ is becoming increasingly common in parts of Africa causing small and moderate-sized outbreaks, especially in Niger. ${ }^{36}$

\section{Diagnosis}

IMD is confirmed by the constellation of clinical presentation, gram staining, and culture of the organism from a normally sterile fluid (such as cerebrospinal fluid, blood, pleural fluid, etc) or by identification using the polymerase chain reaction technique. ${ }^{37,38}$

\section{Treatment and prophylaxis}

First line treatment of IMD is penicillin or ampicillin. ${ }^{1,7}$

Extended spectrum cephalosporins can be used in case of penicillin resistance or if diagnosis remains uncertain. ${ }^{7}$

Rifampicin, ceftriaxone, azithromycin, and quinolones (ciprofloxacin) are used in postexposure chemoprophylaxis for close contacts with the index patient such as in dormitories, military services, hospitals, or schools. ${ }^{7}$

\section{History of vaccine development}

Vaccination remains the best control strategy to prevent IMD, especially in epidemics where postexposure chemoprophy- laxis is not cost effective and increases the chances of antibiotic resistance..$^{8,28}$ There are three types of meningococcal vaccines available in the market: polysaccharide vaccines (MPSV); polysaccharide-protein conjugated vaccines; and, more recently, a new vaccine covering the B serogroup using the bacterium outer membrane proteins.

\section{Polysaccharide vaccines}

The first of the MPSV to be developed was against serogroups $\mathrm{A}$ and $\mathrm{C}$ in response to meningitis epidemics among military recruits in the US in the $1970 \mathrm{~s} .{ }^{39,40}$ Later on, this vaccine was used for outbreak control as well as in hyperendemic regions, in dormitory students, and for travelers to endemic areas. $^{41,42}$

MPSV are currently licensed as bivalent (serogroups A and C), trivalent (serogroups A, C, and W-135), or tetravalent (serogroups A, C, Y, and W-135) vaccines (Table 1). ${ }^{10,43}$ The bivalent and trivalent MPSV are still licensed in Europe but no longer available and were replaced by the quadrivalent polysaccharide vaccines Menomune ${ }^{\circledR}$ (Sanofi-Pasteur, Lyon, France) and Mencevax ${ }^{\circledR}$ (GlaxoSmithKline plc, Brentford, UK). ${ }^{10}$ These two vaccines are also available in the US and Canada. ${ }^{10}$

MPSV are proven to be safe and elicit bactericidal antibodies in older children and adults. ${ }^{44}$ However, these vaccines are poorly immunogenic in infants ${ }^{12,45}$ and prevent building immunological memory because polysaccharides are T-cell-independent antigens that do not stimulate memory $B$ cells. Indeed, MPSV-induced seroprotection is short-lived (1-3 years in children younger than 5 years of age and $3-5$ years in adolescents and adults). ${ }^{39}$ In addition, repeated vaccination was shown to lead to hyporesponsiveness to the vaccine, especially with serogroup $C$, though the clinical implications of such an observation remain unclear. ${ }^{18} \mathrm{MPSV}$ were also shown to have a negligible effect on nasopharyn-

Table I Polysaccharide vaccines

\begin{tabular}{|c|c|c|}
\hline & Serogroups & Manufacturer \\
\hline \multicolumn{3}{|l|}{ Bivalent vaccines } \\
\hline$A C$ vax & $A$ and $C$ & GlaxoSmithKline, plc ${ }^{\mathrm{a}}$ \\
\hline Mengivac & $A$ and $C$ & Sanofi-Pasteur ${ }^{\mathrm{a}}$ \\
\hline \multicolumn{3}{|l|}{ Trivalent vaccines } \\
\hline $\begin{array}{l}\text { Trivalent vaccine } \\
\text { (group A, C, and W-I35) }\end{array}$ & $\mathrm{A}, \mathrm{C}$, and $\mathrm{W}-135$ & GlaxoSmithKline, plc ${ }^{\mathrm{a}}$ \\
\hline \multicolumn{3}{|l|}{ Quadrivalent vaccines } \\
\hline ACWY vax (Mencevax) & $\mathrm{A}, \mathrm{C}, \mathrm{W}-\mathrm{I} 35$, and $\mathrm{Y}$ & GlaxoSmithKline, plc \\
\hline Menomune & $\mathrm{A}, \mathrm{C}, \mathrm{W}-\mathrm{I} 35$, and $\mathrm{Y}$ & Sanofi-Pasteur ${ }^{b}$ \\
\hline
\end{tabular}

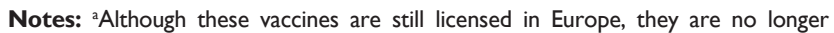
available; bavailable in the USA and Canada. Manufacturer details: GlaxoSmithKline plc, Brentford, UK; Sanofi-Pasteur, Lyon, France. 
geal carriage and hence do not prevent transmission of the organism and do not confer herd immunity. ${ }^{46,47,26}$

Adverse events (AE) related to MPSV are usually mild and include tenderness and erythema at the site of injection lasting for 1-2 days. ${ }^{10,31,48}$ Transient low-grade fever occurs in $<5 \%$ of vaccines. ${ }^{10}$ Serious AE (SAE) include allergic reactions, seizures, and paresthesias but occur in a small percentage of recipients $(<0.1$ per 100,000 doses).

Until recently, MPSV were used in developing countries to control meningococcal epidemics, especially MenA, in Africa and for disease prevention in the Middle East. ${ }^{49}$ As a matter of fact, since the introduction of the quadrivalent polysaccharide meningococcal vaccine in 2002 as a visa requirement for Hajj pilgrims, no outbreak due to IMD has been reported. ${ }^{50}$

In the developed world, MPSV are still used in outbreaks related to vaccine strains and as a preventive measure prior to travel in susceptible patients above 55 years of age with certain host and environmental risk factors such as immunodeficiency and asplenia as well as for military recruits. ${ }^{5,26}$

\section{Multicomponent meningococcal group $B$ vaccine}

The global incidence of MenB disease is high, especially in developed countries. However, as group B polysaccharide is poorly immunogenic due to antigenic mimicry with human neurologic tissues, vaccines against MenB disease have been difficult to produce..$^{51,52}$ None of the conjugate meningococcal vaccines or polysaccharide meningococcal vaccines produced so far have been protective against MenB disease. The only vaccines involving MenB were produced in Cuba, New Zealand, and Norway using the bacterium outer membrane proteins, and these were only used to control epidemics as they were strain specific. ${ }^{53}$ However, in January 2013, Bexsero (Novartis Vaccines, Siena, Italy), a multicomponent meningococcal group B vaccine (ribosomal deoxyribonucleic acid, component, adsorbed), was the first vaccine covering different strains of MenB to be approved by the European Union for use in persons starting at the age of 2 months. ${ }^{54}$ To provide immunity, it uses outer membrane vesicles and lipooligosaccharide noncapsular surface antigens instead of polysaccharides, and contains three recombinant proteins derived from a serogroup B meningococcal strain. This vaccine was found to be immunogenic from infancy through adolescence. ${ }^{55}$ Studies have predicted that this vaccine will cover $78 \%$ of the MenB strains circulating in Europe.$^{56}$ Furthermore, studies have shown that this vaccine can be coadministered with other routine vaccines and has a safety profile that is similar to other vaccines given for the same age group. ${ }^{45,57,58}$

\section{Meningococcal conjugate vaccines}

Since the late 1990s, meningococcal conjugate vaccines (MCV) use has become widespread in the developed world. They are superior to polysaccharide vaccines in eliciting B- and T-cell responses and, thus, provoke immunity in children less than 2 years of age and immunologic memory in all age groups leading to a booster response to subsequent doses. ${ }^{13}$ They induce higher levels of serum bactericidal antibody (SBA) titers and provide long-lasting protection. Unlike MPSV, MCV were also shown to reduce the rate of nasopharyngeal colonization and provide herd immunity. Furthermore, these vaccines do not induce hyporesponsiveness after repeated doses., ${ }^{2,42}$

$\mathrm{MCV}$ are currently available as monovalent group $\mathrm{A}$ or $\mathrm{C}$ vaccines, as well as tetravalent conjugate vaccines (groups A, $\mathrm{C}, \mathrm{W}-135$, and Y [MCV4 qquadrivalent meningoccocal conjugate vaccine $\}]$ ) (Table 2). ${ }^{59}$

\section{Monovalent vaccines}

\section{Meningococcal serogroup A tetanus toxoid conjugate vaccine}

The monovalent MenA conjugate vaccine (MenA-TT, MenAfriVac ${ }^{\circledR}$; Serum Institute of India, Pune, India) has

Table 2 Meningococcal conjugate vaccines

\begin{tabular}{|c|c|c|c|}
\hline Vaccine & Composition & Manufacturer & Age group \\
\hline \multicolumn{4}{|c|}{ Monovalent vaccines } \\
\hline Meningitec & MenC-CRM & Pfizer, Inc. & $\geq 2$ months \\
\hline Menjugate & MenC-CRM & Novartis Vaccines & $\geq 2$ months \\
\hline NeisVac-C & MenC-TT & $\begin{array}{l}\text { Baxter International } \\
\text { Inc. }\end{array}$ & $\geq 2$ months \\
\hline MenAfrivac & MenA-TT & $\begin{array}{l}\text { Serum Institute } \\
\text { of India }\end{array}$ & $\mathrm{I}-29$ years \\
\hline \multicolumn{4}{|c|}{ Quadrivalent vaccines } \\
\hline Menveo & $\begin{array}{l}\text { MenACWY- } \\
\text { CRM }\end{array}$ & Novartis Vaccines & $\begin{array}{l}1 \mathrm{I}-55 \text { years } \\
2-10 \text { years } \\
2-23 \text { months }\end{array}$ \\
\hline Menactra & MenACWY-DT & Sanofi-Pasteur & $\begin{array}{l}1 \mathrm{I}-55 \text { years } \\
2-10 \text { years } \\
9-23 \text { months }\end{array}$ \\
\hline Nimenrix & MenACWY-TT & GlaxoSmithKline, plc & $\geq 12$ months \\
\hline Combination $v$ & accines & & \\
\hline MenHibrix & Hib-MenCY-TT & GlaxoSmithKline, plc & $\begin{array}{l}6 \text { weeks to } \\
18 \text { months }\end{array}$ \\
\hline Menitorix & Hib-MenC-TT & GlaxoSmithKline, plc & $\begin{array}{l}\text { Primary series: } \\
6 \text { weeks to } \\
12 \text { months } \\
\text { Booster: } \\
12 \text { months to } \\
2 \text { years }\end{array}$ \\
\hline
\end{tabular}

Notes: Manufacturer details:Baxter International Inc.,Deerfield,IL,USA;GlaxoSmithKline plc, Brentford, UK; Novartis Vaccines, Siena, Italy; Pfizer, Inc., New York, NY, USA: SanofiPasteur, Lyon, France; Serum Institute of India, Pune, India.

Abbreviations: MenA, meningococcus serogroup $\mathrm{A}$; MenC, meningococcus serogroup C; TT, tetanus toxoid; DT, diphtheria toxin; Hib, hemophilus influenzae serotype b; CRM, corynebacterium diphtheriae toxin, cross-reactive material 197. 
been developed for mass vaccination of the population aged between 1 and 29 years, in particular for Africa where MenA is responsible for outbreaks and more than $80 \%$ of the IMD cases. It was licensed in India in 2009 and launched in Burkina Faso, Mali, and Niger. ${ }^{60}$ In 2010, Burkina Faso was the first country of the meningitis belt to implement mass vaccination with MenA and achieved more than 90\% vaccine coverage in all regions. This campaign resulted in a significant drop in the risk of meningitis and fatal meningitis as it decreased nasopharyngeal carriage. ${ }^{61-64}$

\section{Meningococcal serogroup C conjugate vaccines}

In the mid and late 1990s, the emergence of a hyper-virulent clone of MenC in Canada, the UK, Czech Republic, the Netherlands, Ireland, and Spain caused an increase in disease burden of IMD in these countries. ${ }^{65}$ Following this rise in cases, the UK was the first country to add the MenC vaccine into infants' vaccination schedules, followed later by several other European countries, Australia, and Canada. This measure resulted in a decrease in the incidence of MenC disease that is attributed to the herd immunity achieved by reduction of group $\mathrm{C}$ nasopharyngeal carriage. ${ }^{26}$ Three different single MenC vaccines are commercially available and are detailed in Table $2 .{ }^{10} \mathrm{MenC}$ vaccine was first administered as a three-dose series vaccine at 2, 3, and 4 months of age. However, in 2006, observed waning of postvaccination antibody titers within 1 year of vaccination led the UK National Health Service to recommend the introduction of a booster dose in the $2^{\text {nd }}$ year of life. ${ }^{66}$ Additionally, conjugation of $H$. influenzae type b vaccine and $N$. meningitidis serogroups $\mathrm{C}$ vaccine with TT carrier protein was performed and vaccines are currently available and marketed under the names Menitorix ${ }^{\circledR}$ and MenHibrix ${ }^{\circledR}$ (GlaxoSmithKline plc, Brentford, UK) (Table 2 ). The former is routinely administered to toddlers in the UK, as a booster for MenC vaccination, and the latter was licensed for use as a booster dose at the age of 12 months in the US. ${ }^{67-69}$

\section{Quadrivalent vaccines}

\section{Meningococcal serogroups A, C,W-I35,} and $Y$ diphtheria toxoid conjugate vaccine In 2005, the first meningococcal quadrivalent conjugate vaccine was MenACWY-DT (Menactra ${ }^{\circledR}$; Sanofi-Pasteur). It uses diphtheria toxin as a carrier protein. Meningococcal serogroups A, C, W-135, and Y diphtheria toxoid conjugate vaccine (MenACWY-DT) was licensed for use to vaccinate people aged 11 to 55 years. ${ }^{43}$

In 2007, children 2-10 years old were included in MenACWY-DT vaccination coverage and, since 2011, the age coverage was further extended to include children
9-23 months of age. The latter are given a two-dose series 3 months apart as approved by the US Food and Drugs Administration and recommended by the Advisory Committee on Immunization Practices (ACIP). ${ }^{5,70}$ Individuals from 2 through 55 years of age receive a single dose.

MenACWY-DT was safe and immunogenic when given in two doses to infants and toddlers and showed appropriate immune response, and was given concomitantly with other vaccines without interference with the immune response. ${ }^{71}$ However, later studies have demonstrated waning serum antibody levels and vaccine effectiveness after 5 years of MenACWY-DT administration, especially for serogroups C and $\mathrm{Y}^{72}$ Breakthrough cases of meningococcal disease were reported in older adolescents and adults. ${ }^{73}$

Postlicensure safety evaluation of the vaccine showed that "there might be an excess risk to develop GuillainBarre Syndrome (GBS)", a serious neurological disorder involving inflammatory demyelination of peripheral nerves. ${ }^{74}$ The risk of developing GBS related to vaccine was later evaluated by Velentgas et al following a request from the Centers for Disease Control and Prevention (CDC). ${ }^{75}$ The study demonstrated that there was no evidence of increased risk associated with the MenACWY-DT vaccine. However, caution should be used with persons previously diagnosed with GBS. These subjects may be at increased risk following receipt of MenACWY-DT, and thus should not be vaccinated unless they are at a high risk of meningococcal disease. ${ }^{5,76}$ Until now, the $\mathrm{CDC}$ has recommended a continuation of current vaccination strategies. ${ }^{77}$

\section{Meningococcal serogroups A, C,W-I35, and $Y$ corynebacterium diphtheriae toxin, cross- reactive material 197 conjugate vaccine}

In February 2010, another tetravalent conjugate vaccine using a nontoxic mutant variant of Corynebacterium diphtheriae toxin, cross-reactive material $_{197}$, as a carrier protein (MenACWY$\mathrm{CRM}_{197}$ ) was approved by the US Food and Drug Administration (FDA) and became available in the US and also in Europe (Menveo ${ }^{\circledR}$; Novartis Vaccines, Siena, Italy). ${ }^{78}$ It was approved by the US FDA in persons from 2 to 55 years of age as a single dose. Patients at continuous risk of developing IMD were recommended to get revaccinated every 3-5 years. As of August 2013, the US FDA extended the approval for meningococcal serogroups A, C, W-135, and Y corynebacterium diphtheriae toxin, crossreactive material 197 conjugate vaccine (MenACWY-CRM ${ }_{197}$ ) for use in infants starting at 2 months of age. ${ }^{79,80}$ In October 2013, the ACIP recommended the use of MenACWY-CRM for infants and young toddlers (from the age of 2-23 months) who are at increased risk for meningococcal disease. ${ }^{81}$ 
MenACWY-CRM ${ }_{197}$ induces an immune response that is superior to that induced by MenACWY-DT or MenACWY-PS (quadrivalent polysaccharide meningococcal vaccine). Indeed, in 2010, Stamboulian et al showed that postvaccination antibody titers are consistently higher for MenACWY$\mathrm{CRM}_{197}$, especially against serogroups W-135 and $\mathrm{Y}^{82,83}$

Tolerability outcomes were similar for MenACWY-CRM ${ }_{197}$, MenACWY-DT, and a plain polysaccharide quadrivalent vaccine against meningococcal serogroups A, C, W-135, and Y. The most common adverse event reported was injection-site erythema (19.7\%) followed by injection-site swelling (13.7\%) and syncope (8.8\%). No cases of GBS were reported. ${ }^{5}$

\section{Meningococcal serogroups A, C, W-I 35 and $Y$ tetanus toxoid conjugate vaccine}

Based on the positive experience with conjugation of TT with Hib and MenC vaccines, GlaxoSmithKline plc formulated a third tetravalent conjugate vaccine using TT as a carrier protein: MenACWY-TT. This vaccine is currently licensed under the name of Nimenrix ${ }^{\circledR}$. MenACWY-TT was approved for use in the European Union by the European Medicines Agency in April 2012 and it is recommended throughout the European Union for individuals 12 months of age and above for prevention of IMD. ${ }^{70,84}$

\section{Formulation}

The vaccine comes as a single dose vial containing sterile lyophilized white powder and a single prefilled syringe containing sterile saline and water for intramuscular injection. After reconstitution, one dose of MenACWY-TT $(0.5 \mathrm{~mL})$ contains $5 \mu \mathrm{g}$ each of serogroup A, C, Y, and W polysaccharides conjugated to $44 \mu \mathrm{g}$ of TT carrier protein. Serogroups A and C polysaccharides are conjugated with a spacer molecule (adipic dihydrazide) and indirectly conjugated to the TT whereas the $\mathrm{W}-135$ and $\mathrm{Y}$ polysaccharides are conjugated directly to TT. The vaccine is stored at $2^{\circ} \mathrm{C}-8^{\circ} \mathrm{C}$ (Table 3 ) ${ }^{84}$

\section{Immunogenicity}

Immunogenicity of the vaccine was studied in Phase II and Phase III randomized controlled trials (RCT). The SBA was used as a measure of the immune response in these trials. Rabbit complement SBA (rSBA) was used instead of human complement SBA (hSBA) because it is more readily available. The titer of rSBA that was consistently considered to be protective in these randomized controlled trials was $\geq 1: 8$. Titers were taken prevaccination and 1 month postvaccination to assess vaccine response, which is defined by either rSBA titers $\geq 1: 32$ in initially seronegative subjects or the development of a four-fold increase in these titers from pre- to postvaccination in initially seropositive patients. ${ }^{85}$
Table 3 MenACWY-TT product information

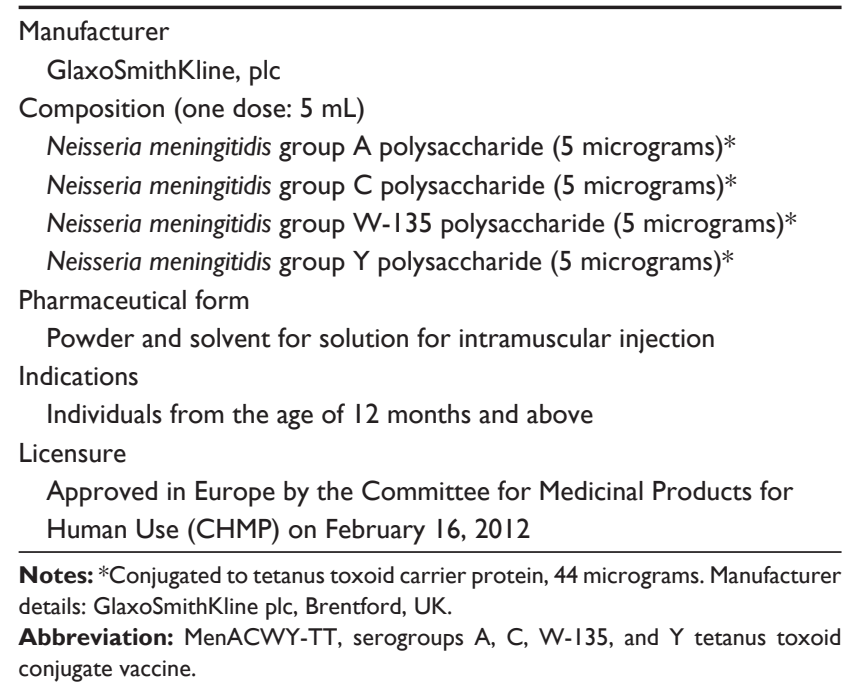

Immunogenicity in infants and toddlers

Several studies were conducted to test the immunogenicity of MenACWY-TT vaccine in toddlers (Tables 4 and 5). ${ }^{86}$

Knuf et al showed that a single dose of four different experimental formulations of MenACWY-TT given to children 12-14 months of age and children 3-5 years of age was immunogenic when compared to MenC-CRM ${ }_{197}$ control vaccine or MenACWY-PS control vaccine, respectively ${ }^{87}$ In fact, rSBA levels taken 1 month postvaccination against all four serogroups were markedly increased with all vaccines. The formulation of MenACWY-TT with the best immune response among all four was used in subsequent clinical trials.

Antibody persistence (rSBA $\geq 1: 8$ ) beyond 15 months after a single dose of MenACWY-TT priming in the above participants was evaluated in an open controlled study conducted in 30 centers in Germany and five centers in Austria. rSBA $\geq 1: 8$ was found in $>92 \%$ of recipients who were aged 12-14 months at the time of vaccination when compared to MenC conjugate vaccine, and in all the children aged 3-5 years when compared to the quadrivalent polysaccharide meningococcal vaccine.$^{88}$ This study also showed that a single dose of MenACWY-TT was immunogenic. ${ }^{88}$

Later, Klein et al ${ }^{89}$ compared the immunogenicity of one dose versus two doses of MenACWY-TT. The vaccine was administered in two different schedules to 385 healthy infants aged 9 months. A single dose given at 12 months of age (ACWY-1) was immunogenic but the two-dose schedule given at 9 and 12 months of age (ACWY-2) achieved higher hSBA titers against all serogroups. At 1 year following vaccination of both groups, protective SBA titers were retained for all serogroups except for serogroup A.

Persistence of the immune response postvaccination was evaluated by Vesikari et al..$^{90}$ In this trial, they showed that 
Table 4 Phase II and Phase III clinical vaccination trials of MenACWY-TT conjugate vaccine in infants, toddlers, and children

\begin{tabular}{|c|c|c|c|c|c|}
\hline Phase & Author & Year & Age group & Country & $\begin{array}{l}\text { Registry number } \\
\text { at Clinicaltrials.gov }\end{array}$ \\
\hline II & Klein et $\mathrm{al}^{89}$ & 2013 & $9-12$ months & United States & NCT0047I08I \\
\hline \multirow[t]{2}{*}{ II } & Vesikari et al ${ }^{90}$ & 2012 & I2-23 months & Finland & NCT00427908 \\
\hline & & & $2-10$ years & Finland & \\
\hline \multirow[t]{2}{*}{ II } & Knuf et a $\left.\right|^{87}$ & 2010 & $12-14$ months & Germany & NCT00I 26984 \\
\hline & & & $3-5$ years & Austria & \\
\hline \multirow[t]{2}{*}{ II } & Knuf et al ${ }^{88}$ & 2012 & $12-14$ months & Germany & NCT00I 26984 \\
\hline & & & $3-5$ years & Austria & \\
\hline II & Dbaibo et $\mathrm{al}^{94}$ & 2012 & $4.5-10$ years & Lebanon & NCT0066I557 \\
\hline \multirow[t]{2}{*}{ III } & Ruiz-Palacios et al ${ }^{105}$ & 2013 & I2-23 months & Taiwan & NCT00758264 \\
\hline & & & & Mexico & \\
\hline III & Vesikari et al $^{91}$ & 2011 & I2-23 months & Finland & NCT00474266 \\
\hline \multirow[t]{3}{*}{ III } & Knuf et al ${ }^{106}$ & 2011 & I2-23 months & Austria & NCT0050826I \\
\hline & & & & Germany & \\
\hline & & & & Greece & \\
\hline \multirow[t]{4}{*}{ III } & Memish et $\mathrm{al}^{93}$ & 2011 & $2-10$ years & Philippines & NCT005I4904 \\
\hline & & & & India & \\
\hline & & & & Lebanon & \\
\hline & & & & Saudi Arabia & \\
\hline \multirow[t]{2}{*}{ III } & Knuf et al ${ }^{95}$ & 2013 & $2-10$ years & Germany & NCT00674583 \\
\hline & & & & France & \\
\hline
\end{tabular}

Abbreviation: MenACWY-TT, serogroups A, C, W-I35, and Y tetanus toxoid conjugate vaccine.

vaccine response was retained for 3 years in the 304 toddlers vaccinated in the $2^{\text {nd }}$ year of life with MenACWY-TT vaccine versus MenC- $\mathrm{CRM}_{197}$ control vaccine. The immunogenicity of the serogroup C component of MenACWY-TT was higher and more persistent than that of the licensed MenC-CRM ${ }_{197}$ vaccine despite the fact that MenACWY-TT contains less polysaccharide antigen than $\mathrm{MenC}-\mathrm{CRM}_{197}{ }^{91}$

Other studies are now ongoing to determine the immunogenicity, reactogenicity, and safety of MenACWY-TT in healthy infants from the age of 6 weeks, in adolescents, and in young adults. These studies are being performed in Lebanon, Mexico, Dominican Republic, and Queensland (Australia).

Immunogenicity in children 2-10 years

Vesikari et al demonstrated noninferiority of MenACWY-TT when compared to MenACWY-PS vaccine in 3-5 year-old children and antibodies persistence for up to 3 years after vaccination. ${ }^{92}$

MenACWY-TT was also noninferior to MenACWY-PS vaccine when administered as a single dose in the study of

Table 5 Phase II and phase III clinical vaccination trials of MenACWY-TT conjugate vaccine in adolescents and adults

\begin{tabular}{|c|c|c|c|c|c|}
\hline Phase & Author & Year & Age group & Country & $\begin{array}{l}\text { Registry number } \\
\text { at Clinicaltrials.gov }\end{array}$ \\
\hline II & Dbaibo et $\mathrm{al}^{94}$ & 2012 & II-34 years & Lebanon & NCT0066I557 \\
\hline II & Ostergaard et $\mathrm{a}^{99}$ & 2013 & $15-19$ years & Denmark & NCT00390I43 \\
\hline II & Baxter et al ${ }^{100}$ & 2011 & $10-25$ years & USA & NCT00454909 \\
\hline \multirow[t]{2}{*}{ II } & Ostergaard et $\mathrm{a}^{96}$ & 2009 & $15-19$ years & Belgium & NCT00I 26945 \\
\hline & & & $18-25$ years & Denmark & NCT00I96950 \\
\hline \multirow[t]{2}{*}{ II } & Borja-Tabora et al ${ }^{98}$ & 2013 & $11-55$ years & Philippines & NCT00356369 \\
\hline & & & & Saudi Arabia & \\
\hline \multirow[t]{2}{*}{ III } & Ostergaard et al ${ }^{103}$ & 2012 & $11-17$ years & Sweden & NCT004658I6 \\
\hline & & & & Denmark & \\
\hline \multirow[t]{3}{*}{ III } & Bermal et a ${ }^{97}$ & 2011 & $11-17$ years & Philippines & NCT004648I5 \\
\hline & & & & India & \\
\hline & & & & Taiwan & \\
\hline \multirow[t]{2}{*}{ III } & Dbaibo et $\mathrm{al}^{85}$ & 2012 & $18-55$ years & Lebanon & NCT00453986 \\
\hline & & & & Philippines & \\
\hline \multirow[t]{2}{*}{ III } & Aplasca-De Los Reyes et al ${ }^{104}$ & 2012 & $18-55$ years & Lebanon & NCT00453986 \\
\hline & & & & Philippines & \\
\hline III & Dbaibo et $\mathrm{al}^{46}$ & 2013 & $56-103$ years & Lebanon & NCTOI 235975 \\
\hline
\end{tabular}

Abbreviation: MenACWY-TT, serogroups A, C, W-135, and $\mathrm{Y}$ tetanus toxoid conjugate vaccine. 
Memish et al conducted on 1,500 subjects in the Philippines, Lebanon, India, and Saudi Arabia. ${ }^{93}$ Immunogenicity for serogroup A was comparable for both whereas immunogenicity for serogroups $\mathrm{C}, \mathrm{W}$, and $\mathrm{Y}$ was higher in the conjugated vaccine group.

Concern about polysaccharide vaccine hyporesponsiveness with repeated doses led investigators to study whether MenACWY-TT immunogenicity is affected in subjects who had previously received PS vaccine. In a Phase II, open, controlled study, Dbaibo et al concluded that MenACWY-TT vaccine induced a protective immune response for all four serogroups in subjects 4.5 to 34 years old previously vaccinated with MenACWY-PS when compared to subjects who had not received a meningococcal vaccine within the past decade. ${ }^{94}$ However, although protective, the titers were significantly lower in the previously PS-vaccinated group.

In an open, randomized, controlled Phase II study in Finland, a protective immune response against meningococcal serogroups A, C, W-135, and $\mathrm{Y}$ was shown to persist up to 3 years following immunization with MenACWY-TT vaccine of healthy children aged $2-10$ years. ${ }^{92}$ In addition, when compared to the control group, the vaccine response rate and postvaccination rSBA geometric mean titers (GMT) were higher for all serogroups among MenACWY-TT recipients than among MenACWY-PS recipients.

Knuf et al showed that the response rate to MenC in MenACWY-TT was noninferior to that of MenC-CRM ${ }_{197}$ vaccine when administered as a single dose to 414 children 2-10 years old. ${ }^{95}$ Although exploratory analyses showed that "there are lower rSBA MenC GMT in the MenACWY-TT group when compared to MenC-CRM ${ }_{197}$ ", $99.3 \%$ of recipients had rSBA titers $\geq 1: 128$ for each of the serogroups; significantly more than the conventional correlate of protection. ${ }^{95}$

\section{Immunogenicity in adolescents and young adults}

The immunogenicity of MenACWY-TT was first evaluated in 2009 in a Phase II study comparing five formulations of experimental MenACWY-TT (differing in both polysaccharide content and in conjugation methods for serogroup $\mathrm{A}$ and C) to MenACWY-PS in adolescents and young adults aged 15-25 years. In this age group, bactericidal titers against all serogroups increased consistently in all five formulations of MenACWY-TT when administered as a single dose. When serogroups $\mathrm{A}$ and $\mathrm{C}$ were conjugated to tetanus toxoid protein without using a linker molecule, a reduced response to MenA component was noticed. ${ }^{96}$

Later, Bermal et al confirmed that the investigational MenACWY-TT vaccine was immunogenic in Asian adolescents between 11 and 17 years old. ${ }^{97}$ This study, conducted in India, the Philippines, and Taiwan, showed that a single dose of MenACWY-TT induced a vaccine response against all the meningococcal serogroups in $\geq 85.4 \%$ of the participants. Noninferiority of MenACWY-TT was demonstrated by further exploratory analysis, which showed significantly higher postvaccination rSBA GMT against all serogroups with MenACWY-TT as compared to MenACWY-PS. ${ }^{97}$

Another Phase IIb study done in Saudi Arabia and the Philippines also confirmed noninferiority of MenACWY-TT compared to MenACWY-PS when administered as a single dose in adolescents and adults. ${ }^{98}$ The rSBA titers for serogroups A, W-135, and Y were significantly higher in patients who received the MenACWY-TT vaccine. When stratified by age group, exploratory analyses did not detect any statistical difference between the two groups and demonstrated that the immune response to the four serogroups persisted up to 3 years postvaccination in 11- to 17-year-old subjects.

Persistence of immune response was also demonstrated by Ostergaard et al. ${ }^{99}$ This study showed that rSBA titers taken 42 months following a single dose of MenACWY-TT administered to adolescents (15-19 years old) were still higher than 1:8 for each serogroup. MenACWY-TT was also proven to be immunogenic when compared to another quadrivalent conjugated meningococcal vaccine: MenACWY-DT. ${ }^{100}$ This study, which was conducted on adolescents and young adults 10-25 years of age, demonstrated that an adequate response was achieved for all serogroups (hSBA titers above the accepted correlate of protection of 1:4) 1 month after vaccination with both vaccines. In fact, MenACWY-TT induced higher hSBA GMT for all four serogroups when compared to MenACWY-DT. ${ }^{100}$

\section{Immunogenicity in older adults}

In a Phase III controlled study conducted in Lebanon and the Philippines, MenACWY-TT was proven to be noninferior to MenACWY-PS when administered to subjects 18-55 years old. Exploratory analysis showed that rSBA GMT were significantly higher than those of MenACWY-PS for serogroups A, W-135, and Y. ${ }^{85}$

In adults above 55 years in age, a single dose of MenACWY-TT was proven to be immunogenic as it achieved rSBA titers against all serotypes $>1: 128$ in more than $93 \%$ of the subjects and was found to induce a vaccine response rate of more than $76 \%$. Exploratory analyses did not show any statistically significant difference between the percentage of response to the two vaccines. However, a difference was established in terms of response magnitude to the vaccine 
as it was significantly lower in MenACWY-TT recipients as related to vaccine rates for serogroup A and rSBA GMT for serogroups A and C. ${ }^{46}$

Another study tried to assess the impact of acetylation of meningococcal serotype A polysaccharide on immunogenicity of the vaccine. This Phase III partially blinded trial was conducted on young adults from 18 to 25 years of age in the Philippines and Thailand. ${ }^{101}$ In this study, subjects were randomized into three different groups. The first group of patients received MenACWY-TT with $68 \%$ O-acetylation of meningococcal serogroup A PS, the second group received MenACWY-TT with 92\% O-acetylation of meningococcal serogroup A PS, and the last group received Men-PS with $82 \%$ O-acetylation of meningococcal serogroup A PS. It was demonstrated that the percentage of acetylation of serotype $A$ polysaccharide did not make any difference in terms of immunogenicity. ${ }^{101}$

\section{Safety and reactogenicity}

Reactogenicity and safety of the MenACWY-TT vaccine was assessed in several studies using diary cards given to subjects or their parents/guardians. Symptoms were recorded using a graded scaling system. Participants were asked to report any local symptom (erythema, induration, or pain) at the site of injection or systemic AE that occurred within 4 days postvaccination. Unsolicited AE and SAE occurring within 31 days postvaccination and throughout the whole study were also recorded respectively. SAE were collected for 6 months postvaccination.

\section{Infants, toddlers and children}

In their study, Knuf et al concluded that there were no statistically significant differences in AE between the MenACWYTT group and MenC-CRM197 control group in toddlers and between the MenACWY-TT group and MenACWY-PS $\left(\right.$ Mencevax $\left.^{\circledR}\right)$ group in young children. ${ }^{87}$

The most frequently recorded solicited general adverse reactions in toddlers after vaccination with MenACWY-TT were irritability (in $15 \%$ of subjects), drowsiness (13\%), and loss of appetite (10\%). In older children (6-10 years), the most frequently reported general adverse reactions were fatigue $(22.3 \%)$, headache $(20 \%)$, gastrointestinal symptoms $(15 \%)$, and fever below $39.5^{\circ} \mathrm{C}(10 \%)$.

In the 1-5 years age stratum, the solicited local adverse reactions were erythema at the injection site (in $35 \%$ of children receiving MenACWY-TT vaccine), followed by pain (28\%), and swelling (27\%). In older children (6-10 years) pain was reported in $43.9 \%$ of children in the MenACWY-TT group; erythema and swelling were also reported in $38 \%$ and $30 \%$, respectively.

Unsolicited AE in toddlers and children included hematoma, rash $(2.6 \%)$, headache, pruritus, pain in an extremity, hypotonia, and gastrointestinal symptoms. ${ }^{87} \mathrm{SAE}$ were recorded in $1.9 \%$ of all recipients of MenACWY-TT vaccine but were not related to vaccination. These events included convulsion, reflux, nasopharyngitis, poisoning, abdominal injury, and appendicitis. ${ }^{95}$

Memish et al conducted a Phase III open, randomized, controlled trial in the Philippines, India, Lebanon, and Saudi Arabia on 1,501, 2-10-year-old subjects. ${ }^{93}$ Subjects were randomized into two age groups -2 to 5 years and 6 to 10 - years and both groups were subdivided into MenACWY-TT and MenACWY-PS groups. MenACWY-TT vaccine was well tolerated in both age strata. Exploratory comparisons revealed no significant difference in solicited local and general symptoms between the two vaccine groups in the $2-5$ years age strata and more overall solicited AE in the 6-10 years age strata. Pain was the main complaint in around $30 \%$ of the MenACWY-PS groups and $20 \%$ of the MenACWY-TT groups.

McVernon et al compared six different experimental formulations of MenACWY-TT to MenC-TT and found that local symptoms were fairly common and occurred in approximately half of all the 360 subjects ( 12 months old) enrolled. ${ }^{102}$ Erythema at the injection site (33\%) and tenderness $(33 \%)$ were frequently reported, while induration was less common. Among general symptoms, irritability (40\%), abnormal crying (40\%), and loss of appetite (40\%) were the most frequently encountered. Those symptoms were comparable among the seven groups. ${ }^{102}$ Vaccination related AE ( 20\%) were also similar between groups. Monoarticular inflammatory arthritis starting 1 day after vaccination was recorded as a possibly related serious adverse reaction in only one subject.

\section{Adolescents and adults}

The incidence of local AE and general symptoms following MenACWY-TT priming was similar to those among MenACWY-DT recipients among subjects 10-25 years old, with pain being the most common local symptom and headache the most common general symptom in both vaccines. ${ }^{100}$ With both vaccines, the rate of new onset chronic illnesses, rash, $\mathrm{AE}$ prompting emergency room visits, and SAE over the 6 months of follow-up postvaccination was low and comparable in all groups. In this study, reactogenicity and safety profiles were proven to be equivalent for both vaccines. 
In patients aged 11-55 years old, no difference was shown in terms of solicited and unsolicited grade III general symptoms between MenACWY-TT and MenACWY-PS groups. ${ }^{98}$ However, the incidence of local AE was higher in the MenACWY-TT group than in the MenACWY-PS group. It was suggested that this was likely due to the TT content of the conjugate vaccine, and the intramuscular route of administration of the conjugate vaccine may play a role in its higher reactogenicity. ${ }^{96,98}$

For older patients, MenACWY-TT is less reactogenic as compared to younger age groups, as is the case with MenACWY-PS. In a study conducted in Lebanon with subjects over the age of 55 years, comparing MenACWY-TT to MenACWY-PS, the incidence of local and general solicited symptoms was less than $3 \%$ in both vaccine groups, with most of them being mild to moderate. The incidence of fever was low in both groups $-2.3 \%$ in the MenACWY-TT and $1 \%$ in MenACWY-PS - and all recordings were below $38^{\circ} \mathrm{C}$ except for one that was $38.5^{\circ} \mathrm{C}$. Rates of $\mathrm{AE}$ and $\mathrm{SAE}$ were very low and no SAE were considered to be vaccine related. ${ }^{46}$

\section{Coadministration}

In general, coadministration of MenACWY-TT $\left(\right.$ Nimenrix ${ }^{\circledR}$ ) with measles, mumps, rubella and varicella vaccine (MMRV) (Priorix-tetra ${ }^{\circledR}$; GlaxoSmithKline plc, Brentford, UK), diphtheria, tetanus, acellular pertussis, hepatitis B, inactivated poliomyelitis, and Haemophilus influenzae type b (Hib) conjugate vaccine (DTPa-HBV-IPV/Hib) (Infanrix-hexa ${ }^{\circledR}$; GlaxoSmithKline plc), or decavalent pneumococcal conjugated vaccine (Synflorix ${ }^{\circledR}$; GlaxoSmithKline plc) in toddlers, with a vaccine against hepatitis A and hepatitis B (Twinrix ${ }^{\circledR}$; GlaxoSmithKline plc) in children and adolescents, and with influenza virus vaccine (Fluarix ${ }^{\circledR}$; GlaxoSmithKline plc) in adults did not affect the immunogenicity of MenACWY-TT or the coadministered vaccine.

\section{Coadministration with a licensed hepatitis $A$ and $B$ vaccine} Coadministration of MenACWY-TT with the licensed hepatitis A and B vaccine (HepA/B) Twinrix ${ }^{\circledR}$ was studied in healthy subjects $11-17$ years of age. ${ }^{103}$ Both vaccines, whether given alone or concomitantly, showed similar vaccine response rates. All subjects vaccinated with HepA/B alone or with MenACWY-TT achieved seropositivity for hepatitis $\mathrm{A}$ and $99.1 \%$ of subjects achieved seroprotection against hepatitis B. It was also demonstrated that the immunogenicity of the MenACWY-TT vaccine, when given concomitantly with the HepA/B vaccine, was noninferior to that of the MenACWY-TT vaccine given alone. In fact, $99.4 \%-100 \%$ of the subjects who received both MenACWY-TT and HepA/B concomitantly showed seroprotection against all meningococcal serogroups. ${ }^{103}$ Furthermore, it was also shown that coadministration of both vaccines did not impact the safety and reactogenicity profile of these vaccines. Therefore, it was concluded that MenACWY-TT is immunogenic, safe, and well tolerated when given alone or concomitantly with HepA/B.

\section{Coadministration with MMRV}

In Finland, Vesikari et al conducted a randomized controlled study to assess the feasibility of coadministration of MenACWY-TT with MMRV. ${ }^{91}$ A total of 1,000 children from 12 to 23 months were enrolled in this study and randomized into different groups in order to assess the immunogenicity and safety of MenACWY-TT when coadministered with MMRV. In this study, MenACWY-TT coadministered with MMRV was shown to be noninferior to MenACWY-TT alone or to MMRV alone. Exploratory analyses did not show any statistically significant differences between the percentages of subjects achieving rSBA GMT in the group given MenACWY-TT concomitantly with MMRV compared to the group given MenACWY-TT alone for any of the four vaccine serogroups.

The response to MMRV components was also assessed. It was found that all subjects who received MMRV either alone or concomitantly with MenACWY-TT had developed seroconversion for all of the vaccine components. Moreover, exploratory analyses showed that there was no statistically significant difference between the two groups except for the anti-rubella geometric mean concentration, which was statistically significantly lower in the group receiving MenACWY-TT concomitantly with MMRV than in the group receiving MMRV alone.

No significant differences were found in terms of safety and tolerability when comparing the coadministration of the two vaccines compared to each alone. It can therefore be concluded that both vaccines can be given concomitantly to patients between 12 and 23 months of age without causing any impact on safety and immunogenicity of either of the two vaccines.

\section{Coadministration with the influenza vaccine}

In adults, coadministration of MenACWY-TT and seasonal influenza vaccine was studied in a double-blinded, controlled, noninferiority study. ${ }^{104}$ In this study, 520 adult subjects were enrolled between the age of 18 and 55 years in order to assess the immunogenicity and safety of coadministration of both vaccines. It was demonstrated that there were no significant differences in the percentages of subjects achieving vaccine response and rSBA titers more than 1:8 or 1:128 for any meningococcal serogroup between the coadministration group and the MenACWY-TT group alone. 
However, exploratory analyses also showed that rSBA GMT were lower in the coadministration group than in the MenACWY-TT group alone for all serogroups, although the difference was only significant for serogroups A and C.

This was possibly related to a potential immune interference between the two vaccines, yet this difference is unlikely to have clinical consequences given that all the subjects achieved adequate vaccine response. In this study, MenACWY-TT was also shown to have an acceptable safety profile, which was not affected by coadministration with the influenza vaccine, and this supports its coadministration to patients at risk of both IMD and influenza disease. ${ }^{104}$

\section{Coadministration with a ten-valent protein conjugated pneumococcal vaccine}

In another study conducted on toddlers aged 12-23 months, immunogenicity of a single dose of MenACWY-TT coadministered with a booster dose of a ten-valent pneumococcal nontypable $H$. influenzae protein D conjugate vaccine (Synflorix $^{\circledR}$; referred to as PCV-10 [10-valent pneumococcal conjugated vaccine]) was compared to PCV-10 alone in subjects who had already received two doses of PCV-10. ${ }^{105}$

MenACWY-TT coadministered with PCV-10 was proven to be noninferior to MenACWY-TT alone and achieved comparable rSBA titers for all four serogroups included in the vaccine.

Similarly, PCV-10, when coadministered with MenACWY-TT, was also found to be noninferior to PCV-10 alone as immune responses against all pneumococcal serotypes were similar to that of PCV-10 alone, except for pneumococcal serotype $18 \mathrm{C}$. This may, however, be of little clinical significance since the antibodies and titer levels increased after the booster of the PCV-10.

The safety profiles for both vaccines, when administered concomitantly, were comparable to those of each vaccine alone. In conclusion, this study showed that coadministration of PCV-10 and MenACWY-TT did not interfere with the immunogenicity, safety, and reactogenicity of these vaccines. $^{105}$

\section{Coadministration with DTPa-HBV-IPV/Hib (Infanrix-hexa ${ }^{\circledR}$ )}

A Phase III open, randomized, controlled trial also studied the possibility of coadministration of MenACWY-TT with DTPaHBV-IPV/Hib in healthy toddlers aged 12-23 months. ${ }^{106}$ In this study, it was demonstrated that coadministration of both vaccines also elicited a strong immune response and was found to be noninferior to MenACWY-TT alone.
Coadministration of both vaccines was also found to be equivalent to administration of MenACWY-TT followed by DTPa-HBV-IPV/Hib 1 month later, and resulted in comparable rSBA antibody GMT against the four meningococcal serogroups.

However, it was also shown that administration of DTPa-HBV-IPV/Hib followed by MenACWY-TT resulted in significantly lower rSBA titers against serogroups A, C, and W-135 when compared to administration of MenACWY-TT followed by DTPa-HBV-IPV/Hib, without, however, leading to lower seroconversion rates. Therefore, this requires further studies to determine the clinical implications of such an observation.

Antibody responses against pertussis, hepatitis B, Hib, diphtheria toxin, tetanus toxin, and poliovirus were also assessed. It was shown that MenACWY-TT, when coadministered with DTPa-HBV-IPV/Hib, was noninferior to DTPaHBV-IPV/Hib followed by MenACWY-TT.

In all the combinations of vaccines included in the study, safety and reactogenicity profiles were found to be similar, hence proving noninferiority of the coadministration of DTPa-HBV-IPV/Hib with MenACWY-TT compared to each of these vaccines alone. ${ }^{106}$

\section{Recommendations for meningococcal vaccination}

Recommendations to vaccinate against IMD vary by country depending on the specific local risks as well as data on vaccine effectiveness and cost-effectiveness.

\section{Recommendations for meningococcal vaccination in the US}

The ACIP recommends the routine vaccination with MenACWY-DT or MenACWY-CRM ${ }_{197}$ of all adolescents aged 11 through 18 years. ${ }^{5}$ A single dose of vaccine should be administered at age 11 or 12 years, with a booster dose at age 16 years for persons who receive the first dose before age 16 years. If the first shot of the vaccine was given at 13-15 years of age, a booster should be given between 16-18 years.

There are other recommendations for special populations at risk for IMD based on age and risk factors. Patients aged 2-23 months at risk for IMD are recommended to receive MenACWY-CRM ${ }_{197}$ in a four-dose series if below 6 months of age or a two-dose series if above that age. MenACWY-DT is recommended as of 9 months of age for children at risk in a two-dose primary series at an interval of 12 weeks. 
Persons at risk for meningococcal disease, aged 9 months to 55 years, should receive MenACWY-DT or MenACWY$\mathrm{CRM}_{197}$ in a one- or two-dose series depending on their underlying medical conditions.

In adults $\geq 56$ years of age, the choice of vaccine type is dependent on whether revaccination will be required. For patients who are not expected to require a second dose of the meningococcal vaccine, the ACIP recommends the use of MenACWY-PS. If multiple doses are anticipated, the ACIP suggests MenACWY-DT or MenACWY-CRM ${ }_{197}$.

For populations who remain at risk of IMD, a booster dose should be administered every 3 years for patients 2 months to 6 years old, or every 5 years for patients more than 7 years of age.

\section{Recommendations for meningococcal vaccination in the UK and the European Union}

In 1999, vaccination of all infants with a conjugate serogroup $\mathrm{C}$ vaccine was established in the UK. The meningococcal vaccine is administered in a three-dose series at 2, 3, and 4 months of age with a catch-up vaccine dose for toddlers and adolescents up to the age of 25 years. Several other countries within the European Union have subsequently also included MenC vaccine in their vaccination schedule

Furthermore, the UK also requires that all those traveling to the Hajj and Umrah as well as travelers to some parts of Africa get vaccinated with a quadrivalent meningococcal vaccine covering the four serogroups, A, C, W, and Y (they recommend administration of MenACWY-CRM ${ }_{197}$ for longer lasting immunity, even if MenACWY-PS is an acceptable option). ${ }^{107}$

In January 2013, a meningococcal serogroup B vaccine was approved by the European Commission for administration to individuals above the age of 2 months. However, the UK's Joint Committee on Vaccination and Immunization advised against adding the meningococcal serogroup B vaccine to the routine vaccination program because this measure was unlikely to be cost-effective..$^{53}$

\section{Conclusion}

In order to decrease the high rate of morbidity and mortality related to IMD, vaccination remains the most important prevention strategy. Among the different meningococcal vaccine types available in the market, MenACWY-TT is an additional option for effective control of infections due to $N$. meningitidis. This vaccine has been consistently shown to provide adequate immunogenicity starting from the age of 12 months and has an acceptable safety profile in different age groups when compared to the other available meningococcal vaccines. It provides long lasting immunity and can be given alone or concomitantly with other childhood vaccines. MenACWY-TT is now available in some European countries and it has been approved by the European Medicines Agency to be given as of 1 year of age to prevent IMD. It is, however, not yet available in the US. Several ongoing studies are assessing its immunogenicity and safety in infants, who are one of the most susceptible groups. This extension of the age group coverage of MenACWY-TT, as well as its wider commercialization in other countries, should widen our tools to achieve a global containment of IMD.

\section{Disclosure}

GSD has served on advisory boards, received grant support through his institution, and received honoraria for lectures from GlaxoSmithKline, Merck Sharpe and Dohme, SanofiAventis, and Pfizer. The authors report no other conflicts of interest in this work.

\section{References}

1. Brouwer MC, Tunkel AR, van de Beek D. Epidemiology, diagnosis, and antimicrobial treatment of acute bacterial meningitis. Clin Microbiol Rev. 2010;23(3):467-492.

2. Baltimore RS. Recent trends in meningococcal epidemiology and current vaccine recommendations. Curr Opin Pediatr. 2006;18:58-63.

3. Pollard AJ. Global epidemiology of meningococcal disease and vaccine efficacy. Pediatr Infect Dis J. 2004;23(Suppl 12):S274-S279.

4. Nadel S. Prospects for eradication of meningococcal disease. Arch Dis Child. 2012;97(11):993-998.

5. Cohn AC, MacNeil JR, Clark TA, et al. Prevention and control of meningococcal disease: recommendations of the Advisory Committee on Immunization Practices (ACIP). MMWR Recomm Rep. 2013; 62(RR-2):1-28.

6. Tzeng YL, Stephens DS. Epidemiology and pathogenesis of Neisseria meningitidis. Microbes Infect. 2000;2(6):687-700.

7. de Souza AL, van de Beek D, Scheld WM. Meningococcal Disease. In: Guerrant RL, Walker DH, Weller PF, editors. Tropical Infectious Diseases: Principles, Pathogens and Practice. 3rd ed. Edinburgh: W.B. Saunders; 2011:174-183.

8. Stephens DS, Greenwood B, Brandtzaeg P. Epidemic meningitis, meningococcaemia, and Neisseria meningitidis. Lancet. 2007;369(9580): 2196-2210.

9. Rouphael NG, Stephens DS. Neisseria meningitidis: biology, microbiology, and epidemiology. Methods Mol Biol. 2012;799:1-20.

10. Granoff DM, Pelton S, Harrison LH. Meningococcal vaccines. In: Plotkin SA, Orenstein WA, Offit PA, editors. Vaccines. 6th ed. London: W.B. Saunders; 2013:388-418.

11. Christensen H, May M, Bowen L, Hickman M, Trotter CL. Meningococcal carriage by age: a systematic review and meta-analysis. Lancet Infect Dis. 2010;10:853-861.

12. Rosenstein NE, Perkins BA, Stephens DS, Popovic T, Hughes JM. Meningococcal disease. N Engl J Med. 2001;344(18):1378-1388.

13. Harrison LH. Prospects for vaccine prevention of meningococcal infection. Clin Microbiol Rev. 2006;19(1):142-164.

14. Keiser PB, Broderick M. Meningococcal polysaccharide vaccine failure in a patient with $\mathrm{C} 7$ deficiency and a decreased anti-capsular antibody response. Hum Vaccin Immunother. 2012;8(5):582-586.

15. Caugant DA, Tzanakaki G, Kriz P. Lessons from meningococcal carriage studies. FEMS Microbiol Rev. 2007;31(1):52-63. 
16. Papaevangelou V, Spyridis N. MenACWY-TT vaccine for active immunization against invasive meningococcal disease. Expert Rev Vaccines. 2012;11(5):523-537.

17. Goldschneider I, Gotschlich EC, Artenstein MS. Human immunity to the meningococcus. II. Development of natural immunity. J Exp Med. 1969;129(6):1327-1348.

18. Tan LK, Carlone GM, Borrow R. Advances in the development of vaccines against Neisseria meningitidis. N Engl J Med. 2010;362(16): $1511-1520$.

19. D’Agati VC, Marangoni BA. The Waterhouse-Friderichsen Syndrome. N Engl J Med. 1945;232(1):1-7.

20. Fellick JM, Sills JA, Marzouk O, Hart CA, Cooke RW, Thomson AP. Neurodevelopmental outcome in meningococcal disease: a case-control study. Arch Dis Child. 2001;85(1):6-11.

21. Pace D, Pollard AJ. Meningococcal disease: clinical presentation and sequelae. Vaccine. 2012;30 Suppl 2:B3-B9.

22. Erickson LJ, De Wals P, McMahon J, Heim S. Complications of meningococcal disease in college students. Clin Infect Dis. 2001;33(5): 737-739.

23. Kimmel SR. Prevention of Meningococcal Disease. Am Fam Physician. 2005;72:2049-2056.

24. Gardner P. Clinical practice. Prevention of meningococcal disease. N Engl J Med. 2006;355(14):1466-1473.

25. Hebert CJ, Hall CM, Odoms LN. Lessons learned and applied: what the 20th century vaccine experience can teach us about vaccines in the 21st century. Hum Vaccin Immunother. 2012;8(5):560-568.

26. Jódar L, Feavers IM, Salisbury D, Granoff DM. Development of vaccines against meningococcal disease. Lancet. 2002;359(9316): 1499-1508.

27. Ramsay M, Kaczmarski E, Rush M, Mallard R, Farrington P, White J. Changing patterns of case ascertainment and trends in meningococcal disease in England and Wales. Commun Dis Rep CDR Rev. 1997;7(4): R49-R54.

28. Rouphael NG, Zimmer SM, Stephens DS. Neisseria meningitidis. In: Barrett ADT, Stanberry LR, editors. Vaccines for Biodefense and Emerging and Neglected Diseases. London: Academic Press; 2009:1061-1079.

29. No authors listed. Meningococcal disease in countries of the African meningitis belt, 2012 - emerging needs and future perspectives. Wkly Epidemiol Rec. 2013;88(12):129-136. English, French.

30. Harrison LH, Trotter CL, Ramsay ME. Global epidemiology of meningococcal disease. Vaccine. 2009;27 Suppl 2:B51-B63.

31. Poland GA. Prevention of meningococcal disease: current use of polysaccharide and conjugate vaccines. Clin Infect Dis. 2010;50 Suppl 2: S45-S53.

32. Lingappa JR, Al-Rabeah AM, Hajjeh R, et al. Serogroup W-135 meningococcal disease during the Hajj, 2000. Emerg Infect Dis. 2003;9(6): 665-671.

33. Borrow R. Meningococcal disease and prevention at the Hajj. Travel Med Infect Dis. 2009;7(4):219-225.

34. Memish ZA, Venkatesh S, Ahmed QA. Travel epidemiology: the Saudi perspective. Int J Antimicrob Agents. 2003;21(2):96-101.

35. Ongoing Struggle with Meningitis W135 in Chile. Available from: http:// healthmap.org/site/diseasedaily/article/ongoing-struggle-meningitisw135-chile-61813. Accessed June 15, 2013.

36. Boisier P, Nicolas P, Djibo S, et al. Meningococcal meningitis: unprecedented incidence of serogroup X-related cases in 2006 in Niger. Clin Infect Dis. 2007;44(5):657-663.

37. Seward RJ, Towner KJ. Evaluation of a PCR-immunoassay technique for detection of Neisseria meningitidis in cerebrospinal fluid and peripheral blood. J Med Microbiol. 2000;49(5):451-456.

38. MacNeil JR. Chapter 8: Meningococcal Disease; Manual for the Surveillance of Vaccine-Preventable Diseases (5th Edition, 2011) [webpage on the Internet]. Atlanta: Centers for Disease Control and Prevention; 2011. Available from: http://www.cdc.gov/vaccines/pubs/ surv-manual/chpt08-mening.html.

39. Joshi VS, Bajaj IB, Survase SA, Singhal RS, Kennedy JF. Meningococcal polysaccharide vaccines: A review. Carbohydr Polym. 2009;75(4):553-565.
40. Girard MP, Preziosi MP, Aguado MT, Kieny MP. A review of vaccine research and development: Meningococcal disease. Vaccine. 2006;24(22):4692-4700.

41. Pace D, Pollard AJ, Messonier NE. Quadrivalent meningococcal conjugate vaccines. Vaccine. 2009;27 Suppl 2:B30-B41.

42. Patel M, Lee CK. Polysaccharide vaccines for preventing serogroup A meningococcal meningitis. Cochrane Database Syst Rev. 2005;(1): CD001093.

43. Croxtall JD, Dhillon S. Meningococcal quadrivalent (serogroups A, C, $\mathrm{W} 135$ and $\mathrm{Y}$ ) tetanus toxoid conjugate vaccine (Nimenrix ${ }^{\mathrm{TM}}$ ). Drugs. 2012;72(18):2407-2430.

44. Shao PL, Chang LY, Hsieh SM, et al. Safety and immunogenicity of a tetravalent polysaccharide vaccine against meningococcal disease. J Formos Med Assoc. 2009;108(7):539-547.

45. Stephens DS. Conquering the meningococcus. FEMS Microbiol Rev. 2007;31(1):3-14.

46. Dbaibo G, El-Ayoubi N, Ghanem S, et al. Immunogenicity and safety of a quadrivalent meningococcal serogroups $\mathrm{A}, \mathrm{C}, \mathrm{W}-135$ and $\mathrm{Y}$ tetanus toxoid conjugate vaccine (MenACWY-TT) administered to adults aged 56 Years and older: results of an open-label, randomized, controlled trial. Drugs Aging. 2013;30(5):309-319.

47. Poolman J, Borrow R. Hyporesponsiveness and its clinical implications after vaccination with polysaccharide or glycoconjugate vaccines. Expert Rev Vaccines. 2011;10(3):307-322.

48. No authors listed. Meningococcal vaccines: WHO position paper, Nov 2011. Wkly Epidemiol Rec. 2011;86(47):521-539. English, French.

49. Sow SO, Okoko BJ, Diallo A, et al. Immunogenicity and safety of a meningococcal A conjugate vaccine in Africans. $N$ Engl J Med. 2011;364(24):2293-2304.

50. Wilder-Smith A. Meningococcal disease: Risk for international travellers and vaccine strategies. Travel Med Infect Dis. 2008;6(4):182-186.

51. Granoff DM. Review of meningococcal group B vaccines. Clin Infect Dis. 2010;50 Suppl 2:S54-S65.

52. Finne J, Leinonen M, Mäkelä PH. Antigenic similarities between brain components and bacteria causing meningitis. Implications for vaccine development and pathogenesis. Lancet. 1983;2(8346):355-357.

53. Kaaijk P, van der Ende A, Luytjes W. Routine vaccination against MenB: Considerations for implementation. Hum Vaccin Immunother. 2013;10(2):1-7.

54. Novartis media releases. Novartis receives EU approval for Bexsero ${ }^{\circledR}$, first vaccine to prevent the leading cause of life-threatening meningitis across Europe [webpage on the Internet]. Basel: Novartis International AG; 2013. Availabe from: http://www.novartis.com/newsroom/mediareleases/en/2013/1672036.shtml. Accessed November 1, 2013.

55. A new MenB (meningococcal $B$ ) vaccine [webpage on the Internet]. Belfast, Bristol, Dublin, Edinburgh: Meningitis Research Foundation; 2013. Available from: http://www.meningitis.org/menb-vaccine. Accessed November 1, 2013.

56. Agency EM. Bexsero. European public assessment report. Meningococcal group B vaccine (rDNA, component, adsorbed) [webpage on the Internet]. Available from: http://www.ema.europa.eu/docs/en_GB/ document_library/EPAR_-_Summary_for_the_public/human/002333/ WC500137857.pdf. Accessed November 1, 2013.

57. Roderick M, Finn A. Advances towards the prevention of meningococcal B disease: A multidimensional story. J Infect. 2014;68 Suppl 1:S76-S82.

58. Novartis International AG. Bexsero Fact sheet. Basel: Novartis International AG. Available from: http://www.novartisvaccines.com/ downloads/meningococcal-disease/Bexsero_Fact_Sheet.pdf. Accessed November 1, 2013.

59. Reisinger KS, Baxter R, Block SL, Shah J, Bedell L, Dull PM. Quadrivalent meningococcal vaccination of adults: phase III comparison of an investigational conjugate vaccine, MenACWY-CRM, with the licensed vaccine, Menactra. Clin Vaccine Immunol. 2009;16(12): 1810-1815.

60. MenAfriCar Consortium, Ali O, Aseffa A, et al. Meningococcal carriage in the African meningitis belt. Trop Med Int Health. 2013;18(8): 968-978. 
61. Frasch CE, Preziosi MP, LaForce FM. Development of a group A meningococcal conjugate vaccine, MenAfriVac(TM). Hum Vaccin Immunother. 2012;8(6):715-724.

62. Trotter CL, Yaro S, Njanpop-Lafourcade BM, et al. Seroprevalence of bactericidal, specific IgG antibodies and incidence of meningitis due to group A Neisseria meningitidis by age in Burkina Faso 2008. PloS One. 2013;8(2):e55486.

63. Centers for Disease Control and Prevention (CDC). Serogroup A meningococcal conjugate vaccine coverage after the first national mass immunization campaign-Burkina Faso, 2011. MMWR Morb Mortal Wkly Rep. 2012;61(50):1022-1024.

64. Novak RT, Kambou JL, Diomandé FV, et al. Serogroup A meningococcal conjugate vaccination in Burkina Faso: analysis of national surveillance data. Lancet Infect Dis. 2012;12(10):757-764.

65. Trotter CL, Ramsay ME, Gray S, Fox A, Kaczmarski E. No evidence for capsule replacement following mass immunisation with meningococcal serogroup C conjugate vaccines in England and Wales. Lancet Infect Dis. 2006;6(10):616-617.

66. Bilukha O, Messonnier N, Fischer M. Use of meningococcal vaccines in the United States. Pediatr Infect Dis J. 2007;26(5):371-376.

67. Borrow R, Abad R, Trotter C, van der Klis FRM, Vazquez JA. Effectiveness of meningococcal serogroup $\mathrm{C}$ vaccine programmes. Vaccine. 2013;31(41):4477-4486.

68. Menitorix - Summary of Product Characteristics [webpage on the Internet]. Uxbridge: GlaxoSmithKline UK; 2005 [updated October 10, 2013]. Available from: http://www.medicines.org.uk/emc/medicine/17189/SPC/. Accessed on October 29, 2013.

69. GlaxoSmithKline. MENHIBRIX (Meningococcal Groups $C$ and $Y$ and Haemophilus b Tetanus Toxoid Conjugate Vaccine). Brentford: GlaxoSmithKline plc; 2012. Available from: http://www.fda.gov/ downloads/BiologicsBloodVaccines/Vaccines/ApprovedProducts/ UCM308577.pdf. Accessed on October 29, 2013.

70. Cramer JP, Wilder-Smith A. Meningococcal disease in travelers: update on vaccine options. Curr Opin Infect Dis. 2012;25(5):507-517.

71. Pina LM, Bassily E, Machmer A, Hou V, Reinhardt A. Safety and immunogenicity of a quadrivalent meningococcal polysaccharide diphtheria toxoid conjugate vaccine in infants and toddlers: three multicenter phase III studies. Pediatr Infect Dis J. 2012;31(11):1173-1183.

72. Committee on Infectious Diseases. Meningococcal conjugate vaccines policy update: booster dose recommendations. Pediatrics. 2011;128(6): 1213-1218

73. Macneil JR, Cohn AC, Zell ER, et al. Early estimate of the effectiveness of quadrivalent meningococcal conjugate vaccine. Pediatr Infect Dis $J$. 2011;30(6):451-455.

74. Centers for Disease Control and Prevention (CDC). Update: GuillainBarre syndrome among recipients of Menactra meningococcal conjugate vaccine - United States, Jun 2005-Sep 2006. MMWR Morb Mortal Wkly Rep. 2006;55(41):1120-1124.

75. Velentgas P, Amato AA, Bohn RL, et al. Risk of Guillain-Barre syndrome after meningococcal conjugate vaccination. Pharmacoepidemiol Drug Saf. 2012;21(12):1350-1358.

76. Smith MJ. Meningococcal tetravalent conjugate vaccine. Expert Opin Biol Ther. 2008;8(12):1941-1946.

77. GBS and Menactra Meningococcal Vaccine [webpage on the Internet]. Atlanta: Centers for Disease Control and Prevention (CDC); 2009 [last updated October 9, 2009]. Available from: http://www.cdc.gov/vaccinesafety/vaccines/gbsfactsheet.html. Accessed on October 15, 2013.

78. Novartis AG. MENVEO ${ }^{\circledR}$ [Meningococcal (Groups A, C, Y and W-135) Oligosaccharide Diphtheria CRM197 Conjugate Vaccine]. Cambridge: Novartis Vaccines and Diagnostics, Inc.; 2010. Available at: http://www. fda.gov/downloads/BiologicsBloodVaccines/Vaccines/ApprovedProducts/UCM201349.pdf. Accessed on October 1, 2013.

79. Novartis International AG. Fda Expands Age Indication for Menveo ${ }^{\circledR}$, First and Only Quadrivalent Meningococcal Vaccine for Infants as Young as 2 Months Of Age. Basel: Novartis International AG; 2013. Available from: http://hugin.info/134323/R/1720709/572916.pdf. Accessed October 1, 2013.
80. Vaccines, Blood and Biologics: Menveo - Approval Letter [webpage on the Internet]. Silver Spring: US Food and Drug Administration; 2013 [last updated September 10, 2013]. Available from: http://www.fda.gov/ BiologicsBloodVaccines/Vaccines/ApprovedProducts/ucm363785.htm. Accessed August 1, 2013.

81. Toy Brown R. ACIP Approves 2014 Child/Adolescent Immunization Schedule. Medscape. Available from: http://www.medscape.com/ viewarticle/813092. Accessed October 23, 2013.

82. Cooper B, DeTora L, Stoddard J. Menveo ${ }^{\circledR}$ ): a novel quadrivalent meningococcal CRM197 conjugate vaccine against serogroups A, C, W-135 and Y. Expert Rev Vaccines. 2011;10(1):21-33.

83. Stamboulian D, Lopardo G, Lopez P, et al. Safety and immunogenicity of an investigational quadrivalent meningococcal CRM(197) conjugate vaccine, MenACWY-CRM, compared with licensed vaccines in adults in Latin America. Int $J$ Infect Dis. 2010;14(10): e868-e875.

84. Nimenrix. European Medicines Agency [webpage on the Internet]. London: European Medicines Agency; 2012 [last updated June 6, 2016]. Available from: http://www.ema.europa.eu/ema/index.jsp?curl=pages/ medicines/human/medicines/002226/human_med_001548. jsp\&mid=WC0b01ac058001d124. Accessed on November 13, 2013.

85. Dbaibo G, Macalalad N, Aplasca-De Los Reyes MR, et al. The immunogenicity and safety of an investigational meningococcal serogroups A, C, W-135, Y tetanus toxoid conjugate vaccine (ACWYTT) compared with a licensed meningococcal tetravalent polysaccharide vaccine: a randomized, controlled non-inferiority study. Hum Vaccin Immunother. 2012;8(7):873-880.

86. Findlow H, Borrow R. Immunogenicity and safety of a meningococcal serogroup A, C, Y and W glycoconjugate vaccine, ACWY-TT. Adv Ther. 2013;30(5):431-458.

87. Knuf M, Kieninger-Baum D, Habermehl P, et al. A dose-range study assessing immunogenicity and safety of one dose of a new candidate meningococcal serogroups A, C, W-135, Y tetanus toxoid conjugate (MenACWY-TT) vaccine administered in the second year of life and in young children. Vaccine. 2010;28(3):744-753.

88. Knuf M, Baine Y, Bianco V, Boutriau D, Miller JM. Antibody persistence and immune memory 15 months after priming with an investigational tetravalent meningococcal tetanus toxoid conjugate vaccine (MenACWY-TT) in toddlers and young children. Hum Vaccin Immunother. 2012;8(7):866-872.

89. Klein NP, Baine Y, Bianco V, et al. One or two doses of quadrivalent meningococcal serogroups a, $\mathrm{C}, \mathrm{w}-135$ and y tetanus toxoid conjugate vaccine is immunogenic in 9- to 12-month-old children. Pediatr Infect Dis J. 2013;32(7):760-767.

90. Vesikari T, Forstén A, Boutriau D, Bianco V, Van der Wielen M, Miller JM. Randomized trial to assess the immunogenicity, safety and antibody persistence up to three years after a single dose of a tetravalent meningococcal serogroups A, C, W-135 and Y tetanus toxoid conjugate vaccine in toddlers. Hum Vaccin Immunother. 2012;8(12): 1892-1903.

91. Vesikari T, Karvonen A, Bianco V, Van der Wielen M, Miller J. Tetravalent meningococcal serogroups A, C, W-135 and Y conjugate vaccine is well tolerated and immunogenic when co-administered with measles-mumps-rubella-varicella vaccine during the second year of life: An open, randomized controlled trial. Vaccine. 2011;29(25): 4274-4284.

92. Vesikari T, Forstén A, Boutriau D, Bianco V, Van der Wielen M, Miller JM. A randomized study to assess the immunogenicity, antibody persistence and safety of a tetravalent meningococcal serogroups $\mathrm{A}, \mathrm{C}, \mathrm{W}-135$ and $\mathrm{Y}$ tetanus toxoid conjugate vaccine in children aged 2-10 years. Hum Vaccin Immunother. 2012;8(12): 1882-1891.

93. Memish ZA, Dbaibo G, Montellano M, et al. Immunogenicity of a single dose of tetravalent meningococcal serogroups A, C, W-135, and $\mathrm{Y}$ conjugate vaccine administered to 2- to 10 -year-olds is noninferior to a licensed-ACWY polysaccharide vaccine with an acceptable safety profile. Pediatr Infect Dis J. 2011;30(4):e56-e62. 
94. Dbaibo G, Van der Wielen M, Reda M, et al. The tetravalent meningococcal serogroups $\mathrm{A}, \mathrm{C}, \mathrm{W}-135$, and $\mathrm{Y}$ tetanus toxoid conjugate vaccine is immunogenic with a clinically acceptable safety profile in subjects previously vaccinated with a tetravalent polysaccharide vaccine. Int J Infect Dis. 2012;16(8):e608-e615.

95. Knuf M, Romain O, Kindler $\mathrm{K}$, et al. Immunogenicity and safety of the quadrivalent meningococcal serogroups A, C, W-135 and $\mathrm{Y}$ tetanus toxoid conjugate vaccine (MenACWY-TT) in 2-10-yearold children: results of an open, randomised, controlled study. Eur J Pediatr. 2013;172(5):601-612.

96. Ostergaard L, Lebacq E, Poolman J, Maechler G, Boutriau D. Immunogenicity, reactogenicity and persistence of meningococcal A, C, W-135 and Y-tetanus toxoid candidate conjugate (MenACWYTT) vaccine formulations in adolescents aged 15-25 years. Vaccine. 2009;27(1):161-168.

97. Bermal N, Huang LM, Dubey AP, et al. Safety and immunogenicity of a tetravalent meningococcal serogroups A, C, W-135 and Y conjugate vaccine in adolescents and adults. Hum Vaccin. 2011;7(2): 239-247.

98. Borja-Tabora C, Montalban C, Memish ZA, et al. Immune response, antibody persistence, and safety of a single dose of the quadrivalent meningococcal serogroups A, C, W-135, and Y tetanus toxoid conjugate vaccine in adolescents and adults: results of an open, randomised, controlled study. BMC Infect Dis. 2013;13:116.

99. Østergaard L, Van der Wielen M, Bianco V, Miller JM. Persistence of antibodies for 42 months following vaccination of adolescents with a meningococcal serogroups A, C, W-135, and $\mathrm{Y}$ tetanus toxoid conjugate vaccine (MenACWY-TT). Int J Infect Dis. 2013;17(3): e173-e176.

100. Baxter R, Baine Y, Ensor K, Bianco V, Friedland LR, Miller JM. Immunogenicity and safety of an investigational quadrivalent meningococcal ACWY tetanus toxoid conjugate vaccine in healthy adolescents and young adults 10 to 25 years of age. Pediatr Infect Dis J. 2011;30(3):e41-e48.

101. Lupisan S, Limkittikul K, Sosa N, et al. Meningococcal polysaccharide A O-acetylation level does not impact the immunogenicity of the quadrivalent meningococcal tetanus toxoid conjugate vaccine (MenACWY-TT): results from a randomized, controlled Phase III study in healthy adults aged 18-25 years. Clin Vaccine Immunol. 2013;20(10):1499-1507.
102. McVernon J, Nolan T, Richmond P, et al. A randomized trial to assess safety and immunogenicity of alternative formulations of a quadrivalent meningococcal (A, C, Y, and W-135) tetanus protein conjugate vaccine in toddlers. Pediatr Infect Dis J. 2012;31(1):e15-e23.

103. Østergaard L, Silfverdal SA, Berglund J, et al. A tetravalent meningococcal serogroups $\mathrm{A}, \mathrm{C}, \mathrm{W}-135$, and $\mathrm{Y}$ tetanus toxoid conjugate vaccine is immunogenic and well-tolerated when co-administered with Twinrix $\left({ }^{\circledR}\right)$ in subjects aged 11-17 years: an open, randomised, controlled trial. Vaccine. 2012;30(4):774-783.

104. Aplasca-De Los Reyes MR, Dimaano E, Macalalad N, et al. The investigational meningococcal serogroups A, C, W-135, Y tetanus toxoid conjugate vaccine (ACWY-TT) and the seasonal influenza virus vaccine are immunogenic and well-tolerated when co-administered in adults. Hum Vaccin Immunother. 2012;8(7):881-887.

105. Ruiz-Palacios GM, Huang LM, Lin TY, et al. Immunogenicity and safety of a booster dose of the 10-valent pneumococcal Haemophilus influenzae protein D conjugate vaccine coadministered with the tetravalent meningococcal serogroups $\mathrm{A}, \mathrm{C}, \mathrm{W}-135$ and $\mathrm{Y}$ tetanus toxoid conjugate vaccine in toddlers: a randomized trial. Pediatr Infect Dis J. 2013;32(1):62-71.

106. Knuf M, Pantazi-Chatzikonstantinou A, Pfletschinger U, et al. An investigational tetravalent meningococcal serogroups A, C, W-135 and Y-tetanus toxoid conjugate vaccine co-administered with Infanrix hexa is immunogenic, with an acceptable safety profile in 12-23-month-old children. Vaccine. 2011;29(25):4264-4273.

107. Vaccination for Meningococcal disease [webpage on the Internet] London: Public Health England; 2013 [last updated July 12, 2013]. Available from: http://www.hpa.org.uk/Topics/InfectiousDiseases/ Infections AZ/MeningococcalDisease/GeneralInformation/ meninvaccinationfactsheet/. Accessed October 1, 2013.
Infection and Drug Resistance

\section{Publish your work in this journal}

Infection and Drug Resistance is an international, peer-reviewed openaccess journal that focuses on the optimal treatment of infection (bacterial, fungal and viral) and the development and institution of preventive strategies to minimize the development and spread of resistance. The journal is specifically concerned with the epidemiology of antibiotic

\section{Dovepress}

resistance and the mechanisms of resistance development and diffusion in both hospitals and the community. The manuscript management system is completely online and includes a very quick and fair peerreview system, which is all easy to use. Visit http://www.dovepress.com/ testimonials.php to read real quotes from published authors. 